\title{
Online integrative negotiation tools for the Dutch Council for Legal Aid
}

\author{
Jelle van VEENEN ${ }^{1}$ \\ Tilburg Institute for Law, Technology, and Society (TILT) \\ Tilburg University
}

\begin{abstract}
This paper describes the background, theoretic model, implementation and use of the Rechtwijzer. The Rechtwijzer ("conflict resolution guide") is the online application of the Dutch Council for Legal Aid. The aim of the application is to help people with a dispute to find a conflict resolution professional that can help, but also to get users to think about their conflict and learn more about their situation. The advice that the application offers is based on integrative negotiation, and should help users to obtain an integrative outcome where possible.
\end{abstract}

Keywords. Online dispute resolution, integrative negotiation

\section{Introduction}

The Rechtwijzer ${ }^{2}$ ("conflict resolution guide") is the internet application through which Dutch citizens seek advice on legal help. The application is the front end of the website of the Dutch council for legal aid, the organization that is responsible for all legal aid in the Netherlands. As a part of this task, the organization offers citizens advice on what steps to take and which legal professionals to contact when they are confronted with a conflict. The council does not offer its users direct legal advice, since that is the responsibility of another organization.

The council was looking for a way to make their services more accessible through the internet, and approached researchers from Tilburg University ${ }^{3}$ to develop an application to this aim. Some important guidelines for the development were:

- the application should help laymen to find the dispute resolution professional that can best help them to solve their conflict;

- the application is based upon the conflict resolution principles of integrative negotiation;

- the application lets users think about their conflict;

- the application does not offer legal advice

The Rechtwijzer was first launched in September 2007 and since then several new functions have been added. In this paper, I describe the functionality at the time of

\footnotetext{
${ }^{1}$ Jelle van Veenen, Tilburg Institute for Law, Technology, and Society (TILT) Tilburg University. E-mail: j.vanveenen@uvt.nl.

2 www.rechtwijzer.nl

${ }^{3}$ The development of the Rechtwijzer was funded and commissioned by the Dutch Council for Legal Aid (raad voor rechtsbijstand, www.rvr.org), Rechtwijzer was developed jointly by the Council, the Tilburg Institute for Interdisciplinary Studies of Civil Law and Conflict Resolution Systems (TISCO), and the Tilburg Institute for Law, Technology, and Society (TILT), both departments of Tilburg University (www.uvt.nl).
} 
writing (November 2007), and I look forward to the extensions that are currently being developed and that are planned for the near future.

\section{Model of Dispute Resolution}

One of the main ideas behind the Rechtwijzer is that every conflict situation is different. A conflict can be caused by all kinds of problems in the interaction between people. The conflict resolution needs of people can be defined as the need to solve the problem (or problems) that lie at the core of the conflict. The aim of the Rechtwijzer is to help people find the conflict resolution professional that can best fulfill their conflict resolution needs.

Apart from offering advice, the Rechtwijzer also has several less visible functions. The first is that, when working on the Rechtwijzer, users let some time pass before they act. This allows them to cool down, and prevents over-emotional users from taking actions that they might regret later on. Secondly, users of the Rechtwijzer are urged to think about the various aspects of their situation. The application helps them to organize their thoughts about the situation and what they need to do. Users who have completed the Rechtwijzer will have a better picture of their situation, their own part in it, and what needs to be done to resolve it. As a result, users may decide to contact, for instance, a mediator, but they may also decide not to contact professional help, and to take further actions by themselves.

The Rechtwijzer is based upon the principles of integrative negotiation; ${ }^{4}$ the idea being that most conflicts can be solved if parties "separate the people from the problem”, "talk about interests, not positions”, “identify options for mutual gain”, and use objective criteria and the BATNA to evaluate options [1]. Based on these principles, a number of actions were defined that can be performed to further the dispute resolution process.

- Improve communication - when parties do not communicate well or do not communicate at all.

- Investigate interests - when the user is not clear on what she wants and needs

- Identify creative options - when the user has given little thought to possible solutions for the situation

- Identify the BATNA - when the user doe not have a clear idea of what will happen if she cannot work something out with the opponent

- Find objective criteria - if the users cannot agree on an outcome, objective criteria can help them to reach a decision.

Each of these actions can be performed by a professional who offers such a service; a mediator might help parties to improve communication, for instance, while a lawyer may help with identifying objective criteria.

Of course, there are also numerous situations where these negotiation techniques are of limited use. In some cases, the conflict requires a binding decision by a third party, or fact finding by an independent expert. Below, all such interventions are listed. Some of the interventions on this list were added specifically to deal with urgent situations: in the case of aggression and in cases were quick action is required, people are immediately referred to a professional.

\footnotetext{
${ }^{4}$ Described in “Getting to yes” [1]. See also the Harvard Project on Negotiation: www.pon.harvard.edu
} 
- Establish facts - when the parties disagree on the circumstances

- Non-binding advice - when the parties need independent advice, but also need to maintain some control over the outcome

- Binding decision - when the situation is such that parties will not reach an agreement by themselves

- Ensure compliance - when there already is an agreement or a binding decision that one of the parties is ignoring

- Record agreements - when parties have reached an agreement but need help to get it recorded officially

- Stop aggression, intimidation, discrimination - urgent referral is needed in cases where there is aggression, intimidation, or discrimination

- Urgent referral - when time limits or possibly serious consequences require that the user contacts a professional immediately

\section{The Application}

The Rechtwijzer consists of a number of components. In this section I will describe the components that are currently fully functional and that are available to the public. Since the launch of the Rechtwijzer in September 2007, we have been improving the application, both on a substantial and on a functional level. In section 5, I will outline the components that are currently being developed.

\subsection{A citizens' guide to legal assistance}

The aim of the Rechtwijzer is to offer citizens advice on what legal professional may be of help in a conflict situation. The advice includes a wide array of legal professionals, ranging from lawyers to mediators and ombudsmen. In order to select the help that is best suited, the application analyses two factors: what is the conflict about and what is the nature of the conflict.

1. What is the conflict about? The first step is to determine the domain of the conflict, so that professionals not active in this field can be filtered out. The Rechtwijzer uses a database with a large number of professionals, but the selection mechanism allows it to give users advice very specific to their situation. In order to determine the situation, the user navigates through a model of the domain by making a series of choices. Each choice further refines the domain definition, until a level is reached where further choices would not result in more specific advice.

The Rechtwijzer currently helps people with a problem on one of five different domains: housing, family, consumer issues, work, and government. For each of these domains, there are several additional levels, which allow the application to determine whether the user has a housing problem concerning an unexpected raise of the rent, or a consumer issue concerning some electric appliance. At this level, we can determine which specific professionals may be of help (dispute resolution committee electric appliances or the rental committee), and also which all-round professionals could be contacted (lawyer or mediator). 


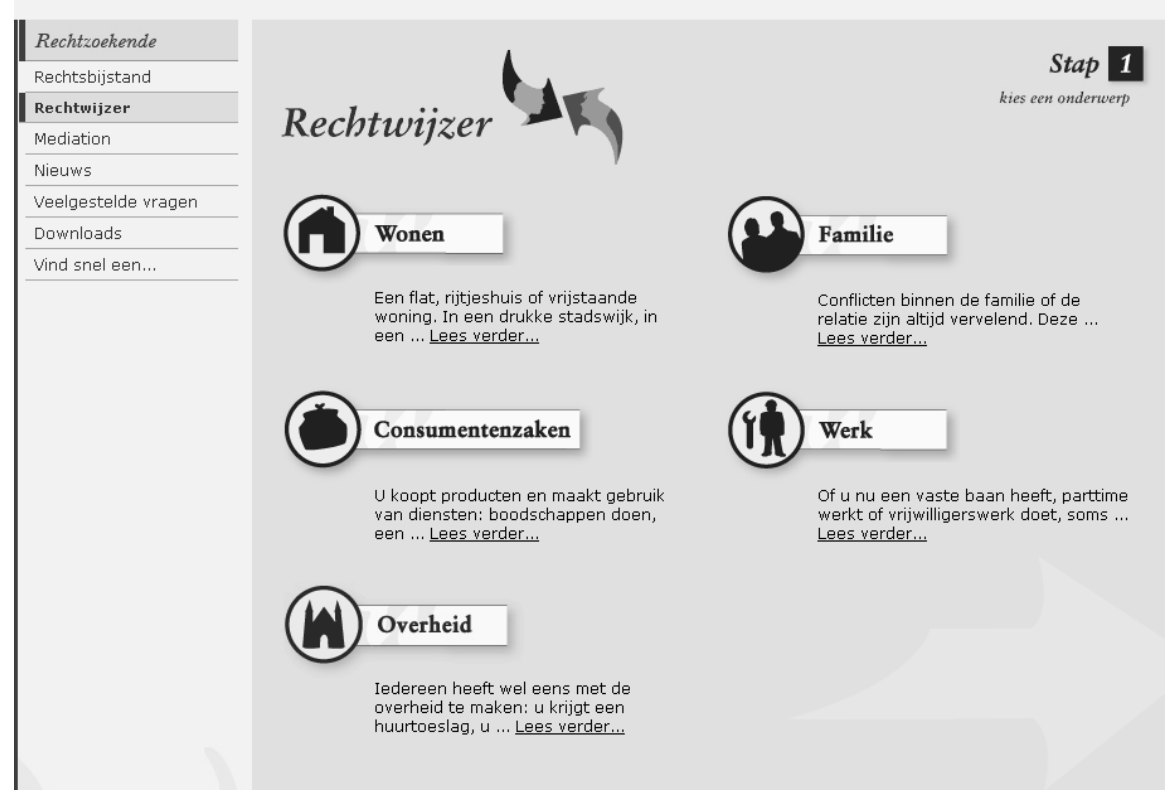

Figure 1: A screenshot from the Rechtwijzer. Here, the application identifies the conflict domain. The user chooses between housing, family, consumer issues, work, and government. Each domain is further refined in a number of steps.

2. What is going wrong? The second stage in finding suitable help is an analysis of the conflict situation. The application asks the user a number of questions to determine what actions (from the conflict resolution model above) are needed.

The figure below shows a question that is used to determine whether help with improving the communication is needed. The question is: "How is the communication with the other?" If the user answers - there is good interaction and we understand each other- or - Normal, there is reasonable interaction- , it is concluded that the action improve communication is not required in this conflict. If the user answers that -interaction is difficult- or -there is no interaction-, it will probably be useful to improve the communication, and so the action improve communication is added to the advice. 


Stap 1 Stap 2
Hoe verloopt het contact met de ander?
OEr is goed contact en we begrijpen elkaar.
OGewoon, het contact verloopt redelijk.
OHet contact verloopt moeilijk.
Kies hebben geen contact meer.

Figure 2: A screenshot from the Rechtwijzer. Here, the user is asked about the interaction with the other party: How is the communication with the other? - There is good interaction and we understand each other Normal, there is reasonable interaction - interaction is difficult - there is no interaction

The figure below shows some advice from the Rechtwijzer. The column on the left lists the actions that are needed in this case, and the top row lists the conflict resolution professionals that may perform (some of) these actions. Both the actions and the professionals are 'clickable'. When a user clicks on an action, he or she gets a further explanation about the action. Clicking a professional results in an overview of the practical information such as the working methods, price, options for legal aid, costs, and contact information.

The Rechtwijzer does not offer the user advice on what single professional to contact. Rather, it offers the users an overview of the things that need to be done, who may do this, and what this may cost. With this information the user herself can choose which of the professionals is best suited for her own (personal, financial) situation.

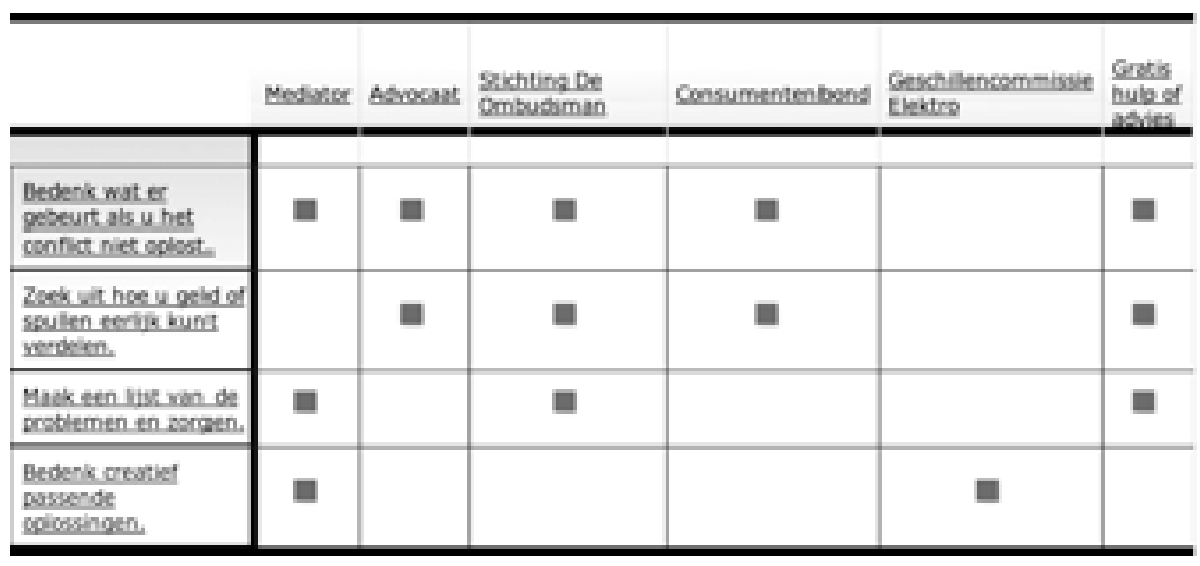

Figure 3: The result of the Rechtwijzer. The table displays which actions are needed to solve a conflict (at the top), and which professionals would be able to deliver such services (to the left). The top line reads: Mediator / Lawyer / Ombudsman / Consumer organization/ Dispute resolution commission electronics / Free help or advice. The column to the left reads: What happens when the conflict is not resolved? / Look for a fair way to divide money or goods / Make a list of issues and worries / Identify creative options. 


\subsection{Communicate needs and wishes to the other party}

Bad communication can get in the way of resolution, and it may even be at the root of a conflict. If a customer is unclear in her description of the problem that she experiences, it will be hard for the customer service to come up with a solution. Someone who starts of with threats where she should be explaining why the situation is such a problem will probably reduce her chances of finding a good solution. Because bad communication is at the source of so many conflicts, a tool was developed for the Rechtwijzer with which users can communicate the most important information to the other party. With this tool users write a letter to the other party which they can send via email or regular mail. This letter serves several purposes: it helps the user to reflect upon the situation, and it helps her to make a clear and effective statement to the other party. The letter should also urge the other party to take her seriously.

The content of the letter is based on the integrative dispute resolution model. Apart from some practical parts, most of the elements of the letter fulfill a function in the integrative negotiation process. The letter includes the following elements:

- There is a problem - The user makes it clear that she is experiencing a problem.

- Product details - Description of the product or service.

- Complaint - What is wrong with the product or service according to the user

- Consequences - here, the user describes the effects that the problem has on her life. When the interests are known, parties can look for a creative solution.

- So far - The user describes what both parties have done so far to solve the situation. She also describes how the interaction has been, and how helpful the other has been.

- What's next - The user sets a date by which she will contact the other, or when she expects the other to contact her. She also makes clear what actions she will take if the dispute is not solved in this way. With this information (from the advice module) she affects the opponent's BATNA, making it clear that serious alternatives are available.

The techniques used for generating the letter are simple; basically, the users' answers are pasted into the letter. While this has some disadvantages (the phrasing of the letter can be a bit awkward, for example), the benefits are great, especially when considering the simplicity of the tool. After working on the letter, users will have a much clearer and organized perception of their situation. The other party will also better understand the users' problems and wishes, and knows that the user is aware of methods for solving the dispute. Research on the effects of the letter on the way that people solve their conflict is being planned, and until now we only have some anecdotal evidence of the effects that it has.

\subsection{Used techniques}

The Rechtwijzer is a relatively simple application. For a large part, the concepts of the Rechtwijzer could be implemented directly in a commercially available knowledgebased system (KBS). Some of the core elements fitted well within the architecture this KBS.

- Establishing the domain To determine what the conflict is about, users navigate a simple tree. 
- Diagnosis The diagnosis of the conflict is based around an evaluation of the need for various actions. This could be implemented straightforward in the knowledge system's logic based reasoning systems. Basically, the answers to the various questions were used as conditions that include or exclude certain actions.

Several parts of the Rechtwijzer however required additional specific features that were not available in the KBS. These features were developed and integrated by the KBS supplier.

- Advice - The Rechtwijzer offers advice on the basis of a database of conflict resolution professionals. For each type of professional, the area of expertise (housing, consumer goods) as well as the services that they can deliver (binding decision, establishing alternatives) are listed. When the domain and the conflict diagnosis are established, the proper professionals can be selected from the database and presented to the user.

- Database of professionals - The Rechtwijzer depends on a complete and up-todate database of dispute resolution professionals, the price of their services, available legal aid, and contact information. Because such information requires careful and regular maintenance, an interface was developed for editing the database.

- Letter - development of the letter also required special development. The implementation of the letter is quite basic. Users answer a number of questions, and the answers are pasted into a standard letter. The letter is formatted and made available for download in the rtf format. This allows the users to edit the letter themselves. This way, users remain some control over the end result. It also takes away the need for users to enter their personal information on the website.

\section{Focus on the user}

The aim of the Rechtwijzer is to help users with a conflict. A lot of care and attention was given to the way that people use the application, and user experiences were gathered to improve both the content and the user interface.

\subsection{User experience}

Extensive use was made of focus groups. At various stages of development, the application was tested by a group of of people representing the target population. These people were given example cases and were instructed to use the Rechtwijzer to decide on their next action. During this they were to think aloud and comment on their experience. This gave the researchers an excellent insight into their experience.

The focus groups proved to be important throughout the development process. One issue that was identified early on regarded the length of the texts. The developers had taken great care to explain all the important steps throughout the application, and to get every question as clear as possible. Focus group research pointed out that the users would simply ignore texts beyond a certain length. In order to cope with this, all text $\mathrm{s}$ were (repeatedly) rewritten, and great care was given to the development of the graphical components of the interface. 
Focus group results showed an increase in users' appreciation; the application is currently rated at a 7.2 by the users. Each month, about 7.500 people open the front page of the website of the Legal Aid Council. Of these people, some 277 complete the entire Rechtwijzer application, and leave with an advice. More research is needed into when and why people leave the application before they finish. Research into the effects that the Rechtwijzer has on the quality of the conflict resolution process of the users is currently being planned.

\section{Future developments}

Several extensions to the Rechtwijzer are planned or underway. One particular example that is currently under development (and will probably be operational at the time of the ODR workshop) is a module for identifying objective criteria.

\section{1. $\quad$ Module for objective criteria}

Objective criteria are a powerful negotiation tool. They offer conflict parties a way to resolve their conflict on the basis of external criteria, which allows them to accept an outcome without risking to lose face. Objective criteria also provide decision makers with a powerful anchor to which they can compare potential outcomes. Realistic criteria increase the likelihood that users accept a realistic outcome.

The Rechtwijzer will be extended with a module for objective criteria. This module will offer information in several forms, depending on the relevant norms. Some criteria may be presented in the form of a calculation tool, where the user only needs to enter the relevant numbers to get an outcome. In other situations, such a clear norm will not be available, and there the Rechtwijzer will offer a description of a reasonable outcome.

The module is currently being developed. This includes development of a method for gathering objective criteria, development of interface components and presentation methods for objective criteria, and empirical research into the effects that objective criteria have on users.

\subsection{Plan of action for divorce}

Over the next year the Rechtwijzer will be extended with a module for handling divorce cases. The module offers a plan of action similar to the PICE system [2]. The plan of action describes all the important issues that the divorcees have to address, and it offers them a set of tools to help them with this process. The plan of action functions as a process management system which guides the user through the divorce process, but it also functions as a communication platform and as a documentation system. Users can communicate through the system, and all agreements are documented there. Users can also access the objective criteria module with specialized knowledge about divorce cases.

Ideally, users would discuss all the issues around their divorce using the plan of action. The may find that they agree on a number of issues, and cannot work out a solution to some others. For those issues they can then consult a professional (which they can find with the advice module). This way costs are reduced, parties remain a greater level of control over the outcome, and the adversarial part of the process is reduced.

We do recognize that a system such as the plan of action will not be suitable for all divorce cases. A test is being developed for assessing the suitability cases. 
Furthermore, the plan of action will be tested in a pilot project under close professional supervision, before it becomes available to the public.

\subsection{Measuring the effects of the Rechtwijzer}

Future plans for the Rechtwijzer also include a study of the effects of the application. Important questions include "are the users happy with the advice they get", "are the users happy with the solution they get after using the Rechtwijzer", and "what is the quality of the solutions that people get when they use the Rechtwijzer". For this end, the instrument developed within the Measuring the Cost and Quality of Access to Justice research project ${ }^{5}$ will be used. This instrument measures the quality of paths to justice on dimensions such as procedural justice and interpersonal justice.

\section{Conclusion}

In this paper, I have introduced the Rechtwijzer application and the ideas that underlie it. Noticeable features of the Rechtwijzer are: 1) the focus is on procedure rather than on knowledge, 2) the model of dispute resolution is based on integrative negotiation and the application advises the user to take actions that help her to reach an integrative outcome, and 3) the Rechtwijzer lets the user think about the conflict situation and organize her thoughts about the problem and possible solutions. The technical implementation of the Rechtwijzer is relatively simple but its use in practice shows that it fulfills a need. The precise effects of the application remain a subject of future study at this point, but stories from users as well as the results of regular testing with focus groups leave us optimistic in this respect.

\section{References}

[1] Fisher, R., W. Ury, et al. (1991). Getting to Yes -Negotiating Agreement Without Giving In. Boston, New York, Houghton Mifflin Company.

[2] Zeeland, C. v., R. Leenes, et al. (2006). Handling Personal Injury Claims - PICE. JURIX 2006, Paris.

[3] Barendrecht, M., J. Mulder, et al. (2006). How to Measure the Price and Quality of Access to Justice? Tilburg, Tilburg University.

\footnotetext{
${ }^{5}$ http://www.tilburguniversity.nl/faculties/law/research/tisco/research/projects/access/ - see also [3]
} 